\title{
Did insecure attachment styles evolve for the benefit of the group?
}

\section{Willem Eduard Frankenhuis*}

Department of Anthropology, University of California at Los Angeles, CA, USA

*Correspondence: wfrankenhuis@gmail.com

\section{A commentary on:}

The attachment paradox: how can so many of us (the insecure ones) have no adaptive advantages?

by Ein-Dor, T., Mikulincer, M., Doron, G., and Shaver, P. R. (2010). Perspect. Psychol. Sci. 5, 123-141.

In a recent article in Perspectives on Psychological Science, Ein-Dor et al. (2010) propose that insecure attachment styles harm the biological fitness of individuals, yet may have been favored by natural selection because they provide benefits for the group. This novel hypothesis proclaims that groups containing a mixture of secure and insecure attachment styles deal more effectively with hazards, such as venomous snakes or fires, because of earlier detection and escape. While I support adaptationist approaches to development, including attachment, I have concerns about this specific proposal. In particular, I question: (1) that insecure attachment styles are detrimental to individual fitness, (2) that insecure attachment styles are well-designed for dealing with danger at the group-level, (3) the underlying assumption that human attachment styles evolved in social groups comprised mostly of genetic relatives, (4) whether the empirical evidence, provided by the authors, can arbitrate between hypotheses postulating benefits to individuals versus benefits to groups.

Ein-Dor et al. (2010) set out to explain an "evolutionary paradox": insecure attachment styles appear harmful to individual fitness, yet they are prevalent in human societies. Studies show that $33-50 \%$ of all humans may be insecurely attached (i.e., anxious, avoidant), across age groups, with higher percentages occurring in populations living in conditions of poverty and instability (Cassidy and Shaver, 1999, 2008; Mikulincer and Shaver, 2007). The solution to the "paradoxical" persistence of insecure attachment styles, according to Ein-Dor et al., is that across evolutionary time, the costs of insecure attachment styles to individuals were exceeded by benefits at the group-level. These group-level benefits are considered a driving selective force, not accidental byproducts of strategies that are individually advantageous hence the paradox. The central idea is that insecure attachment styles are suboptimal to the individual, yet prevalent: this "evolutionary paradox" is resolved by positing group-level benefits. On this view, insecurely attached individuals are evolutionary altruists: they incur a fitness cost to enhance the fitness of other individuals in the group.

Here, I first question the existence of the "attachment paradox" and then the solution proposed by Ein-Dor et al. (2010). For attachment research to benefit from evolutionary biology, it is important that ideas about evolutionary processes, as well as assumptions about our human evolutionary history, are correct and, whenever possible, complete. Thus, an integration of evolutionary and developmental science requires, in addition to empirical studies, conceptual analyses and discussion of key premises.

The hypothesis of Ein-Dor et al. (2010) assumes that insecure attachment styles are maladaptive to the individual: however, the authors do not provide sources to support this claim. To my knowledge, the fitness effects of attachment strategies have never been measured in humans. It would be most informative if studies compared the number of viable offspring (or a different proxy for fitness) of individuals with insecure versus other attachment styles, in conditions in which insecure attachment styles tend to develop. Ideally, such studies would be conducted cross-culturally, in order to ensure results generalize across socio-ecological conditions, or to document and understand variation (Henrich et al., 2010). However, at present, the fitness costs and benefits of different attachment styles are unknown. Therefore, "the attachment paradox" itself is a hypothesis, not a fact requiring explanation. Moreover, some theories suggest that insecure attachment styles can be advantageous to individuals, given particular conditions (e.g., Belsky et al., 1991; Chisholm, 1996; Nettle, 2006; Del Giudice, 2009; Del Giudice and Belsky, 2010). Insecure attachment styles may be adaptive, for instance, if one grows up in a world where people generally provide little support (Belsky et al., 1991; Belsky et al., 2010). Ein-Dor et al. (2010) view their proposal as complementary to this perspective. However, the existing work assumes insecure attachment styles are advantageous to individuals, while EinDor et al. (2010) depart from the exact opposite assumption - the "evolutionary paradox" - making integration difficult. Still, I will argue that even if we grant that insecure attachment styles may harm individual fitness, explaining their evolution in terms of adaptive, group-level benefits, has several problems.

In biology, adaptations are identified when a trait accommodates a presumed function "with sufficient precision, economy, [and] efficiency" (Williams, 1966, p. 10). The proposal of Ein-Dor et al. (2010), in my view, does not meet these criteria. Ein-Dor et al. argue that two major insecure attachment styles - avoidant and anxious - evolved for their grouplevel benefits: "The avoidant pattern may be associated with quick, independent responses to threat, which may at times increase the survival chances of group members by solving the survival problem or demonstrating ways to escape it. The anxious pattern may be associated with sensitivity and quick detection of dangers and threats, which alert other group members to danger and the need for protection or escape" (p. 129). Both these functions 
address some features of insecure attachment styles, such as social withdrawal and high levels of stress. However, they do not address other features that may be fitness-relevant, such as: low self-esteem, greater risk of depression, mixed feelings about relationships, indiscriminate selfdisclosure, ineffective coping strategies, and over-dependence on others. While it may be possible to advance group-level benefits for these features as well, Ein-Dor et al. do not discuss them in depth. In biology, adaptationist accounts are considered most convincing when a close correspondence is revealed between the structure of an adaptive problem and the features of its solution: it is not sufficient to select some features, and hypothesize about their adaptive value, while leaving out other, equally significant ones.

Concerning ancestral social organization, Ein-Dor et al. (2010) assert that all members of a group, "in the environment of evolutionary adaptedness, would often have been genetically related" (p. 124). This premise, if correct, helps their proposal that insecure attachment styles are group-level adaptations, because the costs incurred by altruistic individuals may be compensated by gains in inclusive fitness (Hamilton, 1964): genetic relatives are more likely to share copies of the same alleles, and so helping kin implies furthering one's own reproductive success. However, Ein-Dor et al. (2010) do not provide sources to support their claim that, historically, humans lived in groups composed primarily of kin. To my knowledge, no such sources exist. Unfortunately, the precise characteristics of ancestral social organizations remain largely unknown. If anything, current evidence seems to suggest that humans lived in diverse patterns of social organization, rather than a single one (Schrire, 1980; Foley, 1995; Irons, 1998; Marlowe, 2005; Richerson et al., 2009).

Still, even if we grant that humans would have lived in kin-based households, such households may have co-existed in larger groups consisting of genetically non-related individuals. To what extent the argument of Ein-Dor et al. (2010) formally depends on "kin-groups assumption" is hard to know. Analyzing it requires more detailed specification of the costs and benefits of altruistic strategies in various group compositions (including the ratio of relatives to nonrelatives, and their degrees of relatedness). Biologists have made progress exploring the conditions favoring the evolution of altruism (e.g., Nowak, 2006): yet, much work remains to be done, especially in the domain of large-scale cooperation. It is a merit of Ein-Dor et al. (2010) to invite more discussion about human ancestral social organizations. A better understanding of these contexts may provide insights into the evolved structure of developmental mechanisms, including their dynamic expression across the full breadth of conditions our species experiences (Panchanathan et al., 2010).

Finally, Ein-Dor et al. (2010) present two kinds of evidence - cognitive and behavioral - to support their hypothesis that insecure attachment styles evolved for benefits at the group-level. The cognitive evidence shows that anxiously attached individuals detect potential threats relatively fast and alert others about imminent danger. It also indicates that avoidant individuals initiate self-preservation efforts relatively fast, without relying on the help of other people. Both these empirical results are interesting; however, they do not substantiate that these cognitive aspects are adaptations "for" the benefit of social groups. This is because in each example, individuals may themselves derive a net benefit from their strategy: anxious individuals because early detection of danger facilitates escape, while alerting others can induce collective efforts to ameliorate the threat: avoidant individuals because a focus on autonomous self-preservation may be adaptive, in a world where other people provide little social support (Belsky et al., 1991). Thus, the cognitive evidence cannot distinguish between individual-level and group-level benefits. The behavioral evidence provided by Ein-Dor et al. (2010) employs a smokein-the-room experimental setting, and shows that: "more heterogeneous groups in terms of attachment orientations were ... more effective in dealing with the dangerous situation and took less time to detect and deal with the danger" (p. 135). However, it is not clear why a group-selection perspective would predict that heterogeneous groups perform better than homogeneous groups, composed exclusively of insecurely attached individuals. Is it not the case that a larger number of vigilant eyes is better in dangerous situations?

In sum, while I support adaptationist approaches to development, including attachment, I believe there are significant problems with the hypothesis advanced by Ein-Dor et al. (2010): that insecure attachment styles may be group-selected adaptations for dealing with danger. Despite these doubts, I value the novelty of the hypothesis, and I look forward to future theoretical analyses and empirical tests of the current ideas.

\section{ACKNOWLEDGMENTS}

I thank Robert Bettinger, Ron Dotsch, Richard McElreath, Hiske Hees, Joe Henrich, Sarah Mathew, Karthik Panchanathan, Pete Richerson, and Christopher Stephan for valuable comments.

\section{REFERENCES}

Belsky, J., Houts, R. M., and Fearon, R. M. P. (2010). Infant attachment security and the timing of puberty: testing an evolutionary hypothesis. Psychol. Sci. 21, 1195-1201.

Belsky, J., Steinberg, L., and Draper, P. (1991). Childhood experience, interpersonal development, and reproductive strategy: an evolutionary theory of socialization. Child Dev. 62, 647-670.

Cassidy, J., and Shaver, P.R. (eds). (1999). Handbook of Attachment: Theory, Research, and Clinical Applications. New York: Guilford Press.

Cassidy, J., and Shaver, P.R. (eds). (2008). Handbook of Attachment: Theory, Research, and Clinical Applications, 2nd Edn. New York: Guilford Press.

Chisholm, J. S. (1996). The evolutionary ecology of attachment organization. Hum. Nat. 7, 1-38.

Del Giudice, M. (2009). Sex, attachment, and the development of reproductive strategies. Behav. Brain Sci. 32, 1-67.

Del Giudice, M., and Belsky, J. (2010). Sex differences in attachment emerge in middle childhood: an evolutionary hypothesis. Child Dev. Perspect. 4, 97-105.

Ein-Dor, T., Mikulincer, M., Doron, G., and Shaver, P. R. (2010). The attachment paradox: how can so many of us (the insecure ones) have no adaptive advantages? Perspect. Psychol. Sci. 5, 123-141.

Foley, R. (1995). The adaptive legacy of human evolution: a search for the environment of evolutionary adaptedness. Evol. Anthropol. 4, 194-203.

Hamilton, W.D. (1964). The genetical evolution of social behavior. J. Theor. Biol. 7, 1-52.

Henrich, J., Heine, S. J., and Norenzayan, A. (2010). The weirdest people in the world? Behav. Brain Sci. 33, 61-135.

Irons, W. (1998). Adaptively relevant environments versus the environment of evolutionary adaptedness. Evol. Anthropol. 6, 194-204.

Marlowe, F. W. (2005). Hunter-gatherers and human evolution. Evol. Anthropol. 14, 54-67. 
Mikulincer, M., and Shaver, P. R. (2007). Attachment in Adulthood: Structure, Dynamics, and Change. New York: Guilford Press.

Nettle, D. (2006). The evolution of personality variation in humans and other animals. Am. Psychol. 61, 622-631.

Nowak, M.A. (2006). Five rules for the evolution of cooperation. Science 314, 1560-1563.

Panchanathan, K., Frankenhuis, W. E., and Barrett, H. C. (2010). Development: evolutionary ecology's midwife. Behav. Brain Sci. 33, 105-106.
Richerson, P. J., Boyd, R., and Bettinger, R. L. (2009). Cultural innovations and demographic change. Human Biol. 81, 211-235.

Schrire, C. (1980). An inquiry into the evolutionary status and apparent identity of San hunter-gatherers. Hum. Ecol. 8, 9-32.

Williams, G. C. (1966). Adaptation and Natural Selection. Princeton, NJ: Princeton University Press.

Received:24 September 2010; accepted: 28 September 2010; published online: 01 November 2010.
Citation: Frankenhuis WE (2010) Did insecure attachment styles evolve for the benefit of the group? Front. Psychology 1:172. doi: 10.3389/fpsyg.2010.00172

This article was submitted to Frontiers in Evolutionary Psychology, a specialty of Frontiers in Psychology.

Copyright (c) 2010 Frankenhuis. This is an open-access article subject to an exclusive license agreement between the authors and the Frontiers Research Foundation, which permits unrestricted use, distribution, and reproduction in any medium, provided the original authors and source are credited. 